\title{
Erratum to: Osteoid osteoma and osteoblastoma of the spine: a review of the literature
}

\section{Bernardino Saccomanni}

Published online: 6 March 2012

(C) Springer Science+Business Media, LLC 2012

Erratum to: Curr Rev Musculoskelet Med (2009) 2:1

DOI: $10.1007 /$ s12178-009-9047-6

This article has been retracted due to plagiarism.

B. Saccomanni $(\bowtie)$

Orthopaedic and Traumatologic Surgery,

Gabriele d'Annunzio University, Via dei Vestini,

66013 Chieti Scalo, Italy

e-mail: bernasacco@yahoo.it 